\title{
Improving risk assessment in schizophrenia: epidemiological investigation of criminal history factors
}

Katrina Witt, Paul Lichtenstein and Seena Fazel

\section{Background}

Violence risk assessment in schizophrenia relies heavily on criminal history factors.

\author{
Aims \\ To investigate which criminal history factors are most \\ strongly associated with violent crime in schizophrenia.
}

\section{Method}

A total of 13806 individuals (8891 men and 4915 women) with two or more hospital admissions for schizophrenia were followed up for violent convictions. Multivariate hazard ratios for 15 criminal history factors included in different risk assessment tools were calculated. The incremental predictive validity of these factors was estimated using tests of discrimination, calibration and reclassification.

\section{Results}

Over a mean follow-up of 12.0 years, $17.3 \%$ of men $(n=1535)$ and $5.7 \%$ of women $(n=281)$ were convicted of a violent offence. Criminal history factors most strongly associated with subsequent violence for both men and women were a previous conviction for a violent offence; for assault, illegal threats and/or intimidation; and imprisonment. However, only a previous conviction for a violent offence was associated with incremental predictive validity in both genders following adjustment for young age and comorbid substance use disorder.

\section{Conclusions}

Clinical and actuarial approaches to assess violence risk can be improved if included risk factors are tested using multiple measures of performance.

\section{Declaration of interest \\ None.}

\section{Copyright and usage}

(C) The Royal College of Psychiatrists 2015. This is an open access article distributed under the terms of the Creative Commons Attribution (CC BY) licence.
Although there is strong evidence that patients with schizophrenia are at increased risk of violence compared with the general population, ${ }^{1}$ and current treatment guidelines in both the $\mathrm{UK}^{2}$ and $\mathrm{USA}^{3}$ recommend that violence risk should be assessed in all patients, there is uncertainty over the best method to do this. Current approaches rely on a combination of clinical opinion, which some have argued is unreliable, ${ }^{4}$ and structured tools, which have not been validated in patients with schizophrenia ${ }^{5}$ and have mixed evidence for their predictive accuracy. ${ }^{6}$ In clinical practice, regardless of the approach used, criminal history factors are integral to any assessment. ${ }^{7}$ Consequently all violence risk assessment tools include them and many weight them heavily in deriving risk categories. There is considerable variation, however, in which criminal history items are included and a recent meta-analysis found large differences in their strength of association. ${ }^{8}$ A review of commonly used tools found that 14 different criminal history factors are currently included in existing risk assessment tools. ${ }^{5}$ Identifying the criminal history factor with the most predictive accuracy may, therefore, improve the assessment of risk. We investigated the strength of association for a number of criminal history risk factors using a longitudinal data-set of 13806 individuals diagnosed with schizophrenia over a 22 year period. We also investigated which factors incrementally improved risk prediction beyond known risk factors in men and women separately. We separated genders as recent work suggests that the strength of associated for some criminal history risk factors may differ by gender. ${ }^{9,10}$ In addition, as many patients will not have a criminal history, we investigated whether family criminal factors were associated with violent crime in those without a criminal history before diagnosis with schizophrenia. ${ }^{11}$

\section{Method}

\section{Participants}

Using the ten-digit identification number assigned to all Swedish residents, including migrants, ${ }^{12}$ several Swedish population-based registries were linked. First, the Swedish Hospital Discharge Register (HDR) was used to identify all people diagnosed with schizophrenia according to either the eighth (1973-1986; code 295), ninth (1987-1996; code 295) or tenth (1997 onwards; code F20) revisions of the International Classification of Disease (ICD). ${ }^{13-15}$ The HDR is an accurate record of the prevalence of schizophrenia in Sweden as less than $1 \%$ of discharge records had missing personal identification numbers between 1988 and $2000{ }^{16}$ Additionally, HDR diagnoses demonstrate good concordance when compared with diagnoses made according to DSM-III-R ${ }^{17}$ or DSM-IV criteria. ${ }^{18-20}$ As previous research has used two diagnoses to improve diagnostic specificity, ${ }^{1}$ we included all individuals with at least two separate discharge diagnoses of schizophrenia between 1 January 1973 and 31 December 2004.

Censoring because of death or emigration was identified from the Cause of Death Register (CoD) and Migration Register respectively. The CoD records information on an individual's date, location and cause of death (as recorded on their death certificate) according to the ICD. The CDR has been reported to be $99.7 \%$ complete. $^{21}$ The Migration Register records the date an individual emigrates from Sweden, provided they are leaving for a minimum period of 1 year. $^{22}$

Finally, the Multi-Generation Register (MGR) was used to link each participant to their mother and father. As the MGR records the personal identification number of an individual and their 
parents ${ }^{23}$ it is possible to use the MGR to identify an individual's mother, father and siblings. By linking this information with the National Crime Register (NCR), information on whether an individual's mother, father or siblings have been convicted of any offences in Sweden can also be ascertained. The MGR has good coverage: only $16 \%$ of individuals have missing information on parents. $^{24}$

Statistics Sweden, an independent Government agency, manages the administration of these population registries. This agency merged the registries and assigned each participant an identification number specific to this study. The coding sheet that linked the ten digit identification number to the study identification number was then destroyed to ensure anonymity. ${ }^{25}$ The Karolinska Institutet Ethics Committee gave approval for the study (number: 2005/174-31/4).

\section{Measures}

Violent crime

Data on convictions for violent offences were obtained from the NCR. Coverage of the NCR is complete; only $0.001 \%$ of convictions recorded between 1988 and 2000 were missing personal identification numbers. ${ }^{16}$ Violence was determined from conviction data for two reasons. First, criminal cases cannot be resolved without conviction through plea bargaining or by pleading not guilty by reason of insanity in Sweden. Second, conviction data is recorded in the NCR even if the individual is sentenced to a non-custodial sentence, is transferred to a forensic psychiatric institution at sentencing or receives a fine or caution. ${ }^{26}$ For these reasons the NCR reflects the extent of resolved criminality in Sweden. ${ }^{26}$

Violent convictions were defined as convictions for homicide, aggravated assault, common assault, any sexual assault (for example rape, sexual coercion and child molestation), aggravated robbery, robbery, kidnapping, arson and illegal threats or intimidation. Attempted offences were also included, where relevant. The decision to include threats and intimidation as violent offences is consistent with work in this area. ${ }^{1,16,25-28}$

\section{Criminal history risk factors}

Criminal history risk factors were coded from the crime register. In this study we used risk factors identified from a review of the existing literature ${ }^{8}$ and from a systematic review of items included in existing violence risk assessment tools. ${ }^{5}$ We also investigated other criminal history risk factors that have been used in risk assessment but have not been replicated and are therefore not included in previous reviews (online Tables DS1 and DS2 for men and women, respectively). A full description of the coding used for each criminal history risk factor reported in this study is provided in online Table DS3.

\section{Analyses}

As we were concerned with identifying the criminal history risk factors that predict violence risk in those with schizophrenia, for the purposes of the present study, those convicted of a violent offence subsequent to their diagnosis with schizophrenia were considered to be violent offenders. Individuals were therefore followed from the date of second discharge from hospital with a diagnosis of schizophrenia until conviction for a violent offence, death, emigration or end of follow-up (31 December 2004), whichever came first. We excluded periods in prison and forensic psychiatric hospital from time at risk. As almost all prisoners in Sweden are released on parole after serving two-thirds of their sentence ${ }^{29,30}$ (for sentences over 1 month's duration), time spent in custody was calculated adjusting for this. Only $1.8 \%$ of the custodial sentences received by this cohort were for 1 month or less.

Cox proportional hazards regression was used to investigate the association between each criminal history risk factor and time until conviction for a violent offence. Cox regression generates hazard ratios (HRs) and accompanying 95\% confidence intervals, which represent the ratio of the event rate. The proportional hazards assumption was assessed from the plot of the scaled Schoenfeld residuals. The residuals for all risk factors formed approximately parallel lines, suggesting there were no major violations of the proportionality assumption.

Univariate associations between each criminal history risk factor and violence were calculated separately for men and women. As univariate hazard ratios do not indicate whether a novel risk factor contributes meaningfully to the prediction of risk in clinical practice, ${ }^{31}$ we followed standard guidelines in general medicine for evaluating the incremental validity of novel risk factors, ${ }^{32}$ by investigating their predictive value when added to a baseline model of age and diagnosis with a substance use disorder; based on a lifetime diagnosis on the HDR according to ICD criteria. We chose to adjust for these factors as they have been identified as independently associated with violence risk in prior epidemiological work. ${ }^{1,33}$ Age was measured at the point of the second discharge diagnosis of schizophrenia and was dichotomised as is typically done in risk assessment. We used $<32$ and $\geqslant 32$ years as this cut-off best discriminates risk groups in this data-set. ${ }^{25}$ In a sensitivity analysis, we also modelled age as a linear variable instead of a dichotomous one.

In addition to remaining significantly associated with violence following adjustment for age and comorbid substance use disorder, a clinically important risk factor must also demonstrate an improvement in discrimination, calibration and reclassification. ${ }^{34}$ Consequently, estimates of improvement in discrimination, calibration, and reclassification were calculated for each criminal history risk factor. Discrimination, which refers to the ability of a model to distinguish between those who do and do not have the outcome of interest, was assessed using Harrell's c-index. ${ }^{35}$ The c-index, which ranges from 0.5 to 1 , with 1 demonstrating perfect discrimination, assesses the probability that a violent person scores higher than a non-violent person. ${ }^{36}$ The c-index can be interpreted like an area under the curve (AUC), but has the advantage that it allows for censoring and is therefore preferred for survival analyses. ${ }^{37}$ Calibration, which examines goodness of fit, was assessed statistically using the likelihood ratio test. This indicates whether the addition of a new risk factor significantly improves model fit. Additionally, work also suggests that reclassification, may be important when determining the incremental predictive validity of a novel risk marker. ${ }^{34}$ Reclassification indicates whether the addition of a criminal history risk factor improves the proportion of variance explained by the model, and was assessed using change in Royston's $R^{2} .^{38,39}$ Although there are presently no guidelines to determine how these measures should be combined, in other research a risk factor with the best performance would be the one with the an increase of at least $0.5 \%$ in the c-index, with adequate calibration. ${ }^{40}$ If there were a number of factors that meet these two criteria, we interpreted the risk factor associated with the greatest increase in both the c-index and Royston's $R^{2}$ as important for the assessment of violence risk. All analyses were made using Stata version 11 for Windows.

\section{Subgroup analysis}

Criminal history risk factors were also assessed separately for men with and without a history of criminal conviction prior to 
diagnosis with schizophrenia (online Table DS4). Given the small number of events involved, these additional analyses were not conducted for women.

\section{Results}

We identified 8891 (64.4\%) men and 4915 (35.6\%) women diagnosed with schizophrenia between 1973 and 2004 (Table 1). Average age at diagnosis for men was 29.2 years (s.d. $=7.0$, range 18-48) and for women 29.0 years (s.d. $=7.4$, range 18-49). Average duration of follow-up, excluding years spent in custody, was 11.5 years (s.d. $=8.2$, range $0.08-30.8$ ) for men and 12.7 (s.d. $=8.1$, range $0.1-30.8$ ) for women.

\section{Univariate analyses}

In men, $1535(17.3 \%)$ were convicted of a violent offence. The most common violent conviction for these men was for illegal threats $(45.7 \%$ of violent men), followed by common assault $(33.7 \%)$, sexual offences $(6.3 \%)$, arson $(3.6 \%)$, aggravated assault (3.6\%), robbery $(3.3 \%)$, homicide $(2.7 \%)$ and kidnapping $(1.1 \%)$. Of the criminal history factors identified from previous reviews as being predictive of risk, a previous conviction for assault, a violent offence and having served a term of imprisonment were all strongly associated with violent crime after discharge (Table 2). We also investigated factors included in some risk assessments, although they have not been emphasised in previous systematic reviews, and found some of these were associated with violent crime, notably: conviction for illegal threats and for weapon use. When age was modelled continuously, there were no material changes to these associations (results not presented).

Fewer women were convicted of a violent offence following diagnosis with schizophrenia $(n=281,5.7 \%)$. The most common violent conviction for these women was for threats and intimidation $(43.8 \%)$, followed by common assault $(31.3 \%)$, arson (13.9\%), aggravated assault (6.0\%), homicide (2.5\%), robbery $(1.1 \%)$ and sexual offences $(0.7 \%)$ and kidnapping $(0.7 \%)$. Similar risk factors to those found in men were strongly associated with violence in women. A previous conviction for weapon use, however, was more strongly associated with subsequent violence in women (Table 3). As with men, modelling age as a continuous, rather than as a dichotomous, variable did not materially change these associations (results not presented).

\section{Subgroup analysis}

Of those men with a criminal history prior to diagnosis with schizophrenia $(n=4502,50.6 \%)$, a total of $1051(23.3 \%)$ were convicted of a violent offence during follow-up. The most common conviction was for threats and intimidation $(48.0 \%)$, followed by common assault (32.4\%), sexual offences $(5.4 \%)$, arson $(3.0 \%)$, aggravated assault $(3.7 \%)$, robbery $(3.4 \%)$, homicide $(2.9 \%)$

\begin{tabular}{|c|c|c|c|c|c|c|c|}
\hline \multirow[b]{3}{*}{ Age, years } & \multicolumn{7}{|c|}{$n(\%)$} \\
\hline & \multicolumn{3}{|c|}{ Overall cohort } & \multicolumn{2}{|c|}{ Criminal history prior to diagnosis } & \multicolumn{2}{|c|}{ No criminal history prior to diagnosis } \\
\hline & Total & Men & Women & Men & Women & Men & Women \\
\hline$<20$ & $635(4.6)$ & $409(4.6)$ & $226(4.6)$ & $111(2.4)$ & $22(2.3)$ & $298(6.8)$ & $204(5.2)$ \\
\hline $20-24$ & $3307(24.0)$ & $2215(24.9)$ & $1092(22.2)$ & 908 (20.2) & $146(15.3)$ & $1307(29.8)$ & $946(23.9)$ \\
\hline $25-29$ & $3731(27.0)$ & $2482(27.9)$ & $1249(25.4)$ & $1242(27.6)$ & $224(23.4)$ & $1240(28.2)$ & $1025(25.9)$ \\
\hline$<30$ & $6132(44.4)$ & $3784(42.6)$ & $2348(47.8)$ & $2240(49.8)$ & $565(59.0)$ & $1544(35.2)$ & $1783(45.0)$ \\
\hline Total & $13805^{\mathrm{a}}(100.0)$ & $8890^{\mathrm{a}}(100.0)$ & $4915(100.0)$ & $4501^{a}(100.0)$ & $957(100.0)$ & $4389(100.0)$ & $3958(100.0)$ \\
\hline
\end{tabular}

Table 2 Univariate associations between criminal history risk factors and violent crime in men with schizophrenia ${ }^{\text {a }}(n=8891)$

\begin{tabular}{|c|c|c|c|c|c|c|c|}
\hline \multirow[b]{2}{*}{ Risk factors measured prior to diagnosis } & \multicolumn{2}{|c|}{ Violent, $n$} & \multicolumn{2}{|c|}{ Non-violent, $n$} & \multirow[b]{2}{*}{$\begin{array}{c}\text { Hazard ratio } \\
(95 \% \mathrm{Cl})\end{array}$} & \multirow[b]{2}{*}{$z$} & \multirow[b]{2}{*}{$P$} \\
\hline & $\begin{array}{l}\text { With } \\
\text { risk factor }\end{array}$ & $\begin{array}{l}\text { Without } \\
\text { risk factor }\end{array}$ & $\begin{array}{c}\text { With } \\
\text { risk factor }\end{array}$ & $\begin{array}{l}\text { Without } \\
\text { risk factor }\end{array}$ & & & \\
\hline Conviction for assault & 280 & 1255 & 522 & 6834 & $3.1(2.7-3.6)$ & 17.1 & $<0.001$ \\
\hline Conviction for a violent offence & 509 & 1026 & 1102 & 6254 & $3.1(2.8-3.4)$ & 20.5 & $<0.001$ \\
\hline History of imprisonment (juvenile and/or adult) & 267 & 1268 & 543 & 6813 & $2.9(2.6-3.3)$ & 15.8 & $<0.001$ \\
\hline Conviction for illegal threats and/or intimidation & 220 & 1315 & 479 & 6877 & $2.7(2.4-3.1)$ & 13.6 & $<0.001$ \\
\hline Conviction for weapon use & 119 & 1416 & 267 & 7089 & $2.5(2.1-3.1)$ & 9.7 & $<0.001$ \\
\hline Mother convicted of a violent offence & 23 & 1512 & 41 & 7313 & $2.5(1.7-3.8)$ & 4.4 & $<0.001$ \\
\hline Conviction for a non-violent offence & 803 & 732 & 2303 & 5053 & $2.4(2.2-2.7)$ & 17.4 & $<0.001$ \\
\hline Most recent conviction for a violent offence & 240 & 1295 & 631 & 6725 & $2.2(1.9-2.5)$ & 11.1 & $<0.001$ \\
\hline One or more conviction/s under 18 years of age & 329 & 1206 & 926 & 6430 & $2.0(1.8-2.3)$ & 11.5 & $<0.001$ \\
\hline Parent convicted of a violent offence & 115 & 1420 & 312 & 7042 & $1.9(1.6-2.3)$ & 6.5 & $<0.001$ \\
\hline Most recent conviction for a non-violent offence & 506 & 1029 & 1545 & 5811 & $1.8(1.6-2.0)$ & 10.7 & $<0.001$ \\
\hline Father convicted of a violent offence & 96 & 1439 & 279 & 7075 & $1.8(1.4-2.2)$ & 5.4 & $<0.001$ \\
\hline Conviction for a sexual offence & 24 & 1511 & 82 & 7274 & $1.7(1.1-2.6)$ & 2.7 & $<0.01$ \\
\hline Age at first conviction for any offence ${ }^{\mathrm{b}}$ & & & & & $1.0(1.0-1.0)$ & 2.5 & $<0.05$ \\
\hline Age at first conviction for a violent offence ${ }^{c}$ & & & & & $1.0(1.0-1.0)$ & -2.8 & $<0.01$ \\
\hline
\end{tabular}




\begin{tabular}{|c|c|c|c|c|c|c|c|}
\hline \multirow[b]{2}{*}{ Risk factors measured prior to diagnosis } & \multicolumn{2}{|c|}{ Violent, $n$} & \multicolumn{2}{|c|}{ Non-violent, $n$} & \multirow[b]{2}{*}{$\begin{array}{c}\text { Hazard ratio } \\
(95 \% \mathrm{Cl})\end{array}$} & \multirow[b]{2}{*}{$z$} & \multirow[b]{2}{*}{$P$} \\
\hline & $\begin{array}{l}\text { With } \\
\text { risk factor }\end{array}$ & $\begin{array}{l}\text { Without } \\
\text { risk factor }\end{array}$ & $\begin{array}{l}\text { With } \\
\text { risk factor }\end{array}$ & $\begin{array}{l}\text { Without } \\
\text { risk factor }\end{array}$ & & & \\
\hline Conviction for weapon use & 9 & 272 & 21 & 4613 & $8.7(4.1-18.6)$ & 5.7 & $<0.001$ \\
\hline Conviction for assault & 25 & 256 & 67 & 4567 & $8.5(5.6-12.9)$ & 10.0 & $<0.001$ \\
\hline Conviction for a violent offence & 54 & 227 & 160 & 4474 & $8.0(5.9-10.8)$ & 13.4 & $<0.001$ \\
\hline History of imprisonment (juvenile and/or adult) & 9 & 272 & 26 & 4608 & $7.3(3.6-14.9)$ & 5.5 & $<0.001$ \\
\hline Most recent conviction for a violent offence & 39 & 242 & 116 & 4518 & $7.1(5.1-10.1)$ & 11.2 & $<0.001$ \\
\hline Conviction for illegal threats and/or intimidation & 18 & 263 & 56 & 4578 & $6.5(3.9-10.8)$ & 7.2 & $<0.001$ \\
\hline One or more conviction/s under 18 years of age & 29 & 252 & 127 & 4507 & $4.5(3.0-6.7)$ & 7.4 & $<0.001$ \\
\hline Conviction for a non-violent offence & 94 & 187 & 566 & 4068 & $4.1(3.2-5.3)$ & 11.2 & $<0.001$ \\
\hline Mother convicted of a violent offence & 4 & 277 & 23 & 4611 & $3.0(0.9-9.6)$ & 1.8 & 0.06 \\
\hline Most recent conviction for a non-violent offence & 66 & 215 & 486 & 4148 & $2.9(2.2-3.9)$ & 7.7 & $<0.001$ \\
\hline Parent convicted of a violent offence & 21 & 260 & 187 & 4447 & $2.0(1.3-3.2)$ & 3.1 & $<0.01$ \\
\hline Father convicted of a violent offence & 18 & 263 & 169 & 4465 & $1.9(1.2-3.2)$ & 2.6 & $<0.01$ \\
\hline Age at first conviction for a violent offence ${ }^{b}$ & & & & & $1.0(1.0-1.1)$ & 1.1 & 0.26 \\
\hline Age at first conviction for any offence ${ }^{c}$ & & & & & $1.0(1.0-1.0)$ & 3.8 & $<0.001$ \\
\hline
\end{tabular}

and kidnapping (1.2\%). The factors most strongly associated with violence in this group were similar to those for men in the overall cohort (Table DS3).

None of the familial criminal history risk factors were significantly associated with increased violence risk for those men who were not convicted of a violent offence prior to diagnosis with schizophrenia $(n=4389,49.4 \%)$ (results not presented).

\section{Discrimination, calibration, and reclassification analyses}

We investigated all the factors for discrimination, calibration and reclassification. This analysed whether they added incremental predictive accuracy to a baseline model of young age ( $<32$ years) and comorbid substance use disorder. We found that a previous conviction for a violent offence is an important risk factor for this population as it was associated with the greatest increase in the c-index and Royston's $R^{2}$, although adjusted hazard ratios were similar to those for some other factors (Tables 4 and 5). For men, the adjusted hazard ratio for previous violent conviction was 2.3 (95\% CI 2.1-2.6), resulting in a c-index of 69.4 for the adjusted model including age and comorbid substance use disorder. For women, the adjusted hazard ratio for a previous violent conviction was 5.1 (95\% CI 3.7-7.2). When included in a model with age and substance use disorder, this led to a c-index of 69.6. When age was modelled as continuously, similar results were found for both genders (results not presented).

In a second model (Alternate model 2, Table 4), we investigated the incremental predictive validity of adding the remaining criminal history factors to a model that included young age, comorbid substance use disorder and conviction for a violent offence. For this model, collinear variables were not included, and although adjusted hazard ratios were significant, small increases in both the c-index and Royston's $R^{2}$ were observed for most variables. In women (Alternate model 2, Table 5), however, adding a history of a non-violent offence may improve prediction. When age was measured continuously, there was no material difference to these findings (results not presented).

For men with a history of criminal offending prior to diagnosis, a previous conviction for a violent offence was also associated with the largest increase in the c-index (results not presented).

\section{Discussion}

Criminal history risk factors are frequently weighted most heavily in the assessment of violence risk. Previous work, however, suggests there is considerable variability in the strength of association for these risk factors in those with psychosis. ${ }^{8}$ In this study, we examined which of these previously identified criminal history factors best predicted conviction for a violent crime in a population cohort of 13806 individuals with schizophrenia who were followed for an average of 12 years.

This study provides some precision as to the relative strength of different criminal history risk factors in individuals with schizophrenia. Although univariate analyses showed that a number of criminal history risk factors were associated with violent crime in both men and women with schizophrenia, when these were added to a baseline model incorporating young age and comorbid substance use disorder, a history of violent conviction led to the greatest increase in discrimination (which indicates the probability that a violent individual scores higher than a non-violent individual), calibration (which indicates goodness of fit) and reclassification (which can be interpreted as indicating the change in predicted risk for an individual following the addition of a novel risk factor). ${ }^{41}$

In contrast to expert opinion, ${ }^{9,10}$ results of the present study suggest that similar criminal history risk factors are associated with violence in both men and women with schizophrenia. However, the relative strength of these risk factors appears to differ by gender. A conviction for weapon use, for example, was more strongly associated with violence in females (unadjusted $\mathrm{HR}=8.7$ ) than in males (unadjusted $\mathrm{HR}=2.5$ ). This is likely because of the low base rates of such risk factors in women, and in our study $0.6 \%$ of women were convicted for weapon use compared with $4.3 \%$ of men.

One implication of our study is that it demonstrates the importance of looking beyond univariate analyses in the construction of risk prediction rules. We have proposed one approach to this, which has been validated in cardiovascular 
Table 4 Incremental validity of criminal history risk factors in predicting violent crime in men with schizophrenia ${ }^{a}(\boldsymbol{n}=\mathbf{8 8 9 1})$

\begin{tabular}{|c|c|c|c|c|c|c|c|c|}
\hline \multirow[b]{2}{*}{ Risk factors measured prior to diagnosis } & \multirow{2}{*}{$\begin{array}{l}\text { Adjusted hazard } \\
\text { ratio }(95 \% \mathrm{Cl})\end{array}$} & \multirow[b]{2}{*}{$P$} & \multicolumn{2}{|c|}{ Harrell's c-index } & \multicolumn{2}{|c|}{ Likelihood ratio } & \multicolumn{2}{|c|}{ Adjusted Royston's $R^{2}$} \\
\hline & & & $\%(95 \% \mathrm{Cl})$ & $\Delta \%$ & $\Delta \chi^{2}$ & $P$ & $\%(95 \% \mathrm{Cl})$ & $\Delta \%$ \\
\hline \multicolumn{9}{|l|}{$\begin{array}{l}\text { Baseline model: young age + comorbid substance } \\
\text { use disorder }\end{array}$} \\
\hline + Conviction for violent offence & $2.3(2.1-2.6)$ & $<0.001$ & & +4.2 & 193.1 & $<0.001$ & & +6.8 \\
\hline + Conviction for assault & $2.2(1.9-2.6)$ & $<0.001$ & & +2.2 & 114.9 & $<0.001$ & & +4.1 \\
\hline + History of imprisonment (juvenile and/or adult) & $1.9(1.6-2.2)$ & $<0.001$ & & +1.7 & 71.9 & $<0.001$ & & +2.6 \\
\hline + Conviction for illegal threats and/or intimidation & $1.9(1.7-2.3)$ & $<0.001$ & & +1.7 & 67.3 & $<0.001$ & & +2.4 \\
\hline + Mother convicted for a violent offence & $1.9(1.3-3.0)$ & $<0.01$ & & +0.2 & 8.2 & $<0.01$ & & +1.9 \\
\hline + Most recent conviction for a violent offence & $1.8(1.6-2.1)$ & $<0.001$ & & +2.4 & 65.0 & $<0.001$ & & +2.4 \\
\hline + Conviction for weapon use & $1.8(1.5-2.2)$ & $<0.001$ & & +1.0 & 31.0 & $<0.001$ & & +1.1 \\
\hline + Conviction for a non-violent offence & $1.7(1.5-1.9)$ & $<0.001$ & & +3.9 & 87.9 & $<0.001$ & & +3.2 \\
\hline + Parent convicted for a violent offence & $1.7(1.4-2.0)$ & $<0.001$ & & +0.5 & 24.0 & $<0.001$ & & +0.9 \\
\hline $\begin{array}{l}\text { + Father convicted for a violent offence } \\
\text { + One or more conviction/s for any offence }\end{array}$ & $1.6(1.3-2.0)$ & $<0.001$ & & +0.3 & 17.2 & $<0.001$ & & +0.6 \\
\hline under 18 years of age & $1.5(1.3-1.7)$ & $<0.001$ & & +1.3 & 32.7 & $<0.001$ & & +1.2 \\
\hline + Conviction for a sexual offence & $1.4(0.9-2.2)$ & 0.13 & & +0.2 & 2.4 & 0.12 & & +0.1 \\
\hline + Most recent conviction for a non-violent offence & $1.3(1.2-1.5)$ & $<0.001$ & & +2.2 & 22.5 & $<0.001$ & & +0.8 \\
\hline \multicolumn{9}{|l|}{ Alternate model: young age + comorbid substance } \\
\hline + Mother convicted for a violent offence & $1.6(1.0-2.5)$ & $<0.05$ & & +0.1 & 4.5 & $<0.05$ & & +0.3 \\
\hline + Conviction for a non-violent offence & $1.4(1.3-1.6)$ & $<0.001$ & & +2.1 & 38.9 & $<0.001$ & & +1.5 \\
\hline + History of imprisonment (juvenile and/or adult) & $1.4(1.2-1.6)$ & $<0.001$ & & +0.5 & 18.7 & $<0.001$ & & +0.8 \\
\hline + Parent convicted of a violent offence & $1.4(1.2-1.8)$ & $<0.001$ & & +0.2 & 13.1 & $<0.01$ & & +0.6 \\
\hline + Father convicted of a violent offence & $1.4(1.1-1.7)$ & $<0.01$ & & +0.1 & 9.4 & $<0.01$ & & +0.5 \\
\hline $\begin{array}{l}\text { + Most recent conviction for a non-violent offence } \\
+ \text { One or more conviction/s for any offence }\end{array}$ & $1.3(1.2-1.4)$ & $<0.001$ & & +0.9 & 21.3 & $<0.001$ & & +0.9 \\
\hline under 18 years of age & $1.1(1.0-1.3)$ & $<0.05$ & & +0.4 & 4.7 & $<0.05$ & & +0.3 \\
\hline
\end{tabular}

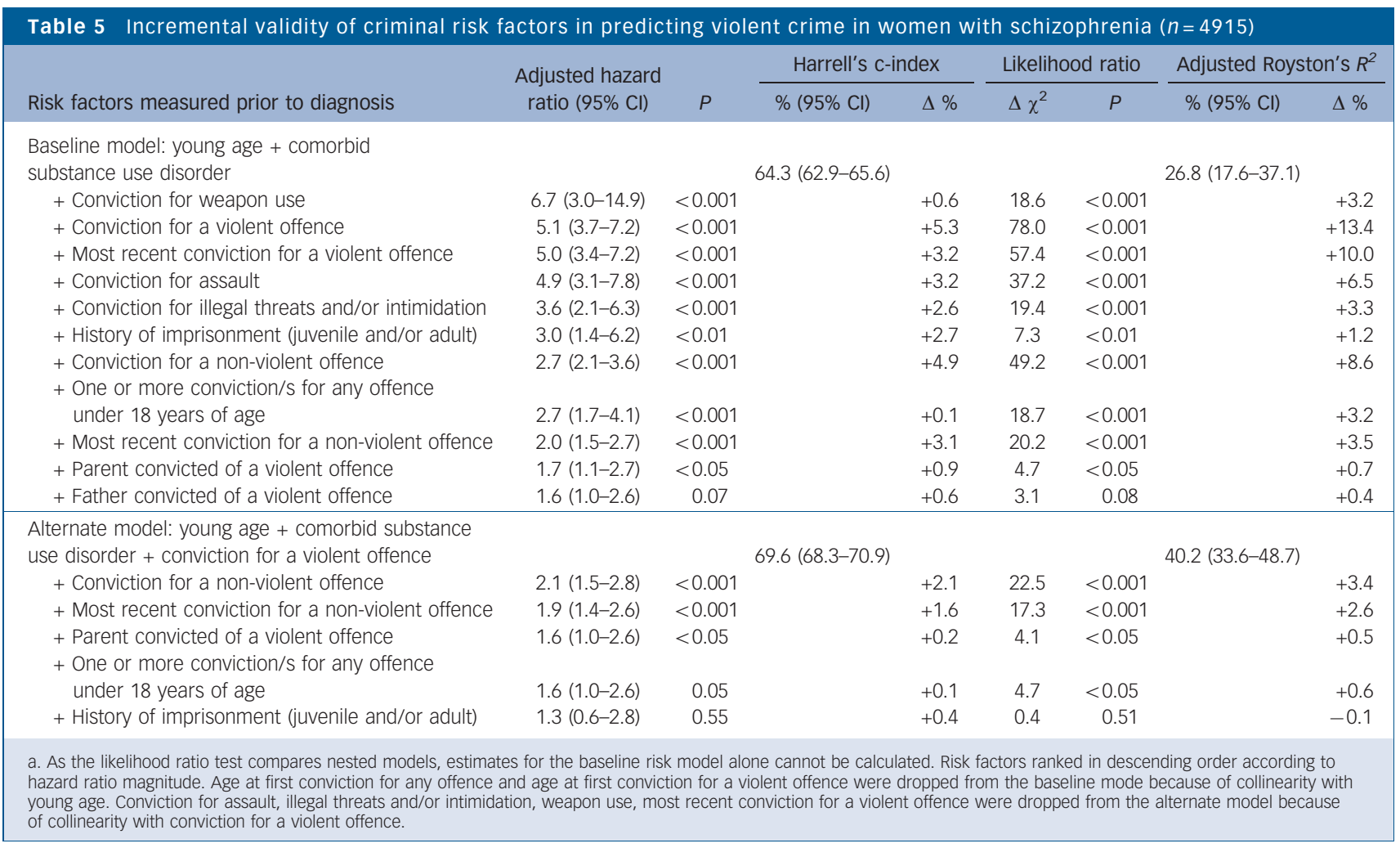

medicine, ${ }^{32}$ where the incremental predictive accuracy to existing risk models needs to be examined. Thus, we would suggest that future work should investigate whether any novel risk factors add to a baseline risk model that includes young age, comorbid substance misuse and a previous violent conviction.
Although all currently used violence risk assessment instruments include criminal history items, ${ }^{5}$ we found that a number of the items included in these instruments may not contribute to the prediction of violence in schizophrenia. These factors included previous convictions for sexual offences 
in men and possibly a parental history of violent offending in women.

In a subgroup analysis, we investigated whether the relative strength of these criminal history risk factors varied for men with and without a criminal history prior to diagnosis with schizophrenia. In men with a criminal history, similar risk factors were significantly associated with violence risk. In those without an offending past, no familial criminal history factors were significantly associated with violence risk.

The causes of violence are multifactorial, however, reflecting a number of genetic, historical, environmental and clinical risk factors. ${ }^{42}$ The assessment of violence risk in this population should be sensitive to the interplay of various background factors, and individual differences in how they have an impact on patients. It is therefore important to highlight that the pathways and mechanisms leading to violence in patients with schizophrenia should not be reduced to one set of risk factors. However, the focus of the current study is the assessment of violence risk rather than its aetiology, and we have investigated which of the heavily weighted criminal history factors should be part of clinical risk assessment.

\section{Strengths and limitations}

The use of nationwide data enabled this study to achieve a sample size that is several orders of magnitude larger than previous investigations into criminal history risk factors for violence in individuals with schizophrenia. A novel feature of this approach is that the present study was able to investigate risk factors for violent crime separately for women with schizophrenia. To our knowledge, only one other study of 304 women with psychosis has done this, and found that a history of imprisonment was significantly associated with subsequent violence but, contrary to our findings, that assault was not. ${ }^{43}$

Criminal history risk factors analysed in this study were coded from official register-based data. Therefore, the prevalence of violence in this study may underestimate the true extent of criminality in this population. ${ }^{26}$ As this was not a study of prevalence but of risk factors, however, the use of relatively hard outcome measures means that findings may be generalisable to non-Scandinavian countries. Furthermore, it also allowed for a larger sample and longer follow-up than a study based on clinical interviews with patients. However, it does mean that more sensitive measures of violence that did not lead to conviction were not included, and their relative contribution to risk prediction needs further research. When more sensitive measures have been used, such as a combination of both self- and collateral-reported violence, previous violence also represented the strongest indicator of subsequent violence risk. ${ }^{44}$

Another limitation is that we restricted our cohort to patients admitted to hospital on at least two separate occasions with schizophrenia. This is consistent with previous work using this cohort. Additionally, this decision was made to improve diagnostic specificity. This meant that although all crimes before second diagnosis were included in our analyses, these were, however, classified as criminal history factors. Further work will therefore need to investigate whether our findings are generalisable to first-episode psychosis. We have shown previously that there are similar base rates of violence in those individuals with only one discharge diagnosis for schizophrenia as compared with those with two or more diagnoses, ${ }^{1}$ suggesting some generalisablity.

The prevalence of schizophrenia in Sweden is very similar to that reported from other high-income countries according to a large meta-analysis. ${ }^{45}$ In addition, the median prevalence rate of the broader category of psychosis at 1.0\% has little variation across European countries. ${ }^{46}$ Finally, age-adjusted disability-adjusted life years (DALYs) for schizophrenia are very close for Sweden (186), the UK (185) and the USA (186). ${ }^{47}$ Sweden also has similar rates of violent crime per head of population compared with most Western European countries, ${ }^{48}$ although it does have a lower rate of homicide than countries with more liberal gun ownership laws such as the USA. ${ }^{16}$ As homicide is rare (accounting for $2 \%$ of the violent convictions in our sample), our findings are more relevant to general psychiatry than research focusing on homicide outcomes.

The most common conviction in our cohort was for threats and/or intimidation. This high proportion is not dissimilar to one other study, based on mentally ill offenders convicted of more serious violent offences in England and Wales. ${ }^{49}$ Other population studies on the association between violence and schizophrenia have not reported individual offence categories. ${ }^{50}$ Further work on the prevalence of individual violent offence types is therefore required to ascertain the generalisability of this finding to other jurisdictions. Finally, although have been no major changes to the definition for different offences within the Swedish legal system over the previous decade, the precise legal categories will vary by country.

\section{Implications}

This study suggests that a conviction for a violent crime prior to diagnosis may be the strongest predictor of subsequent convictions for violence in those with schizophrenia. Clinical assessment should prioritise this factor among the criminal factors investigated, and risk assessment tools should consider incorporating it into their schemes. Novel risk factors for predicting violence in schizophrenia need to consider incremental predictive validity beyond baseline models that include previous violent conviction, young age and comorbid substance misuse.

\section{Katrina Witt, DPhil, Department of Psychiatry, University of Oxford, Warneford Hospital, Oxford, UK; Paul Lichtenstein, PhD, Department of Medical Epidemiology and Biostatistics, Karolinska Institutet, Stockholm, Sweden; Seena Fazel, MD, Department of Psychiatry, University of Oxford, Warneford Hospital, Oxford, UK \\ Correspondence: S. Fazel, University of Oxford, Department of Psychiatry, Warneford Hospital, Oxford, OX3 7JX, UK. Email: seena.fazel@psych.ox.ac.uk First received 7 Jan 2014, final revision 24 Jul 2014, accepted 19 Sep 2014\#\#}

\section{Funding}

S.F. is supported by the Wellcome Trust (095806). P.L. is supported by the Swedish Council for Working Life and Social Research.

\section{Acknowledgements}

The authors are grateful to Christine Norby who extracted the data, the late Martin Grann for defining the criminal history variables and Daniel Lunn for statistical advice.

\section{References}

1 Fazel S, Långström N, Hjern A, Grann M, Lichtenstein P. Schizophrenia, substance abuse and violent crime. JAMA 2009; 301: 2016-23.

2 National Institute for Health and Clinical Excellence. Core Interventions in the Treatment and Management of Schizophrenia in Primary and Secondary Care. NICE, 2009

3 American Psychiatric Association. Practice Guidelines for the Treatment of Patients with Schizophrenia. APA, 2004.

4 Murray J, Thompson M. Clinical judgement in violence risk assessment. Eur J Psychol 2010; 1: 128-49.

5 Singh JP, Serper M, Reinharth J, Fazel S. Structured assessment of violence risk in schizophrenia and other psychiatric disorders: a systematic review of 
the validity, reliability and item content of 10 available instruments. Schizophr Bull 2011; 37: 899-912.

6 Fazel S, Singh JP, Doll H, Grann M. Use of risk assessment instruments to predict violence and antisocial behaviour in 73 samples involving 24827 people: systematic review and meta-analysis. BMJ 2012; 345: e4692.

7 Walsh E, Buchanan A, Fahy T. Violence and schizophrenia: examining the evidence. Br J Psychiatry 2002; 180: 490-5.

8 Witt K, van Dorn R, Fazel S. Risk factors for violence in psychosis: systematic review and meta-regression analysis of 110 studies. PLOS One 2013; 8 e55942.

9 Hastings ME, Krishnan S, Tangney JP, Stuewig J. Predictive and incremental validity of the Violence Risk Appraisal Guide scores with male and female jail inmates. Psychol Assess 2011; 23: 174-83.

10 Sturup J, Monahan J, Kristiansson M. Violent behaviour and gender of Swedish psychiatric patients: a prospective clinical study. Psychiatric Serv 2013; 64: 688-93.

11 Kooyman I, Walsh E, Stevens H, Burns T, Tyrer P, Tattan T, et al. Criminal offending before and after the onset of psychosis: examination of an offender typology. Schizophr Res 2012; 140: 198-203.

12 Lunde AS, Lundeborg S, Lettenstrom GS, Thygesen L, Huebner J. The personnumber systems of Sweden, Norway, Denmark and Israel. Vital Health Stat 2 1980; 2: 1-59.

13 World Health Organization. International Statistical Classification of Disease and Related Health Problems (ICD-8). WHO, 1967.

14 World Health Organization. International Statistical Classification of Diseases and Related Health Problems (ICD-9). WHO, 1978.

15 World Health Organization. The ICD-10 Classification of Mental and Behavioural Disorders: Diagnostic Criteria for Research. WHO, 1993.

16 Fazel S, Grann M. The population impact of severe mental illness on violen crime. Am J Psychiatry 2006; 163: 1397-403.

17 Vares M, Ekholm A, Sedvall GC, Hall H, Jönsson EG. Characterization of patients with schizophrenia and related psychoses: evaluation of different diagnostic procedures. Psychopathology 2006; 39: 286-95.

18 Dalman C, Broms J, Cullberg J, Allebeck P. Young cases of schizophrenia identified in a national inpatient register: are the diagnoses valid? Soc Psychiatry Psychiatr Epidemiol 2002; 37: 527-31.

19 Ekholm B, Ekholm A, Adolfsson R, Vares M, Osby U, Sedvall GC, et al. Evaluation of diagnostic procedures in Swedish patients with schizophrenia and related psychoses. Nord J Psychiatry 2005; 59: 457-64.

20 Lichtenstein P, Bjork C, Hultman C, Scolnick E, Sklar P, Sullivan PF. Recurrence risks for schizophrenia in a Swedish National Cohort. Psycho Med 2006; 36: 1417-25.

21 Johansson LA, Westerling R. Comparing Swedish hospital discharge records with death certificates: Implications for mortality statistics. Int J Epidemiol 2000; 29: 495-502.

22 Miettunen J, Suvisaari J, Haukka J, Isohanni M. Use of register data for psychiatric epidemiology in the Nordic countries. In Textbook of Psychiatric Epidemiology (3rd edn) (ed MT Tsuang, M Tohen and PB Jones). John Wiley \& Sons, 2011

23 Statistics Sweden, Population and Welfare Department. Multi-Generation Register 2010. A Description of Contents and Quality. Statistics Sweden, 2011

24 Statistics Sweden, Population and Welfare Department. Multi-Generation Register 2009. A Description of Contents and Quality. Örebro, Sweden; 2010.

25 Singh JP, Grann M, Lichtenstein $\mathrm{P}$, Långström N, Fazel S. A novel approach to determining violence risk in schizophrenia: developing a stepped strategy in 13,806 discharged patients. PLOS One 2012; 7: e31727.

26 Fazel S, Grann M, Carlstrom E, Lichtenstein P, Långström N. Risk factors for violent crime in schizophrenia: a national cohort study of 13,806 patients. J Clin Psychiatry 2009; 70: 362-9.
27 Fazel S, Lichtenstein P, Grann M, Goodwin GM, Långström N. Bipolar disorder and violent crime: new evidence from population-based longitudinal studies and systematic review. Arch Gen Psychiatry 2010; 67: 931-8.

28 Grann M, Fazel S. Substance misuse and violent crime: Swedish population study. BMJ 2004; 328: 1233-4.

29 Lappi-Seppälä T, Tonry M. Crime, criminal justice, and criminology in the Nordic countries. In Crime and Justice in Scandinavia (eds M Tonry and T Lappi-Seppälä). University of Chicago Press, 2011.

30 van Hofer $\mathrm{H}$, Tham $\mathrm{H}$. Punishment in Sweden: a changing penal landscape. In Punishment in Europe: A Critical Anatomy of Penal Systems (eds V Ruggiero and M Ryan). Palgrave Macmillian, 2013.

31 Grund B, Sabin C. Analysis of biomarker data: logs, odds ratios and ROC curves. Curr Opin HIV AIDS 2010; 5: 473-9.

32 Hlatky MA, Greenland P, Arnett DK, Ballantyne CM, Criqui MH, Elkind MSV et al. Criteria for evaluation of novel markers of cardiovascular risk: a scientific statement from the American Heart Association. Circulation 2009; 119: 2408-16.

33 Swanson JW, Swartz MS, Van Dorn RA, Elbogen EB, Wagner HR, Rosenheck $\mathrm{RA}$, et al. A national study of violent behavior in persons with schizophrenia. Arch Gen Psychiatry 2006; 63: 490-9.

34 Ioannidis JPA, Tzoulaki I. What makes a good predictor? The evidence applied to coronary artery calcium score. JAMA 2010; 303: 1646-7.

35 Harrell FEJ. Regression Modeling Strategies with Applications to Linear Models, Logistic Regression, and Survival Analysis. Springer-Verlag, 2001.

36 Maltoni M, Scarpi E, Pittureri C, Martini F, Montanari L, Amaducci E, et al. Prospective comparison of prognostic scores in palliative care cancer populations. Oncologist 2012; $17: 446-54$

37 Pencina MJ, D'Agostino RB. Overall $C$ as a measure of discrimination in survival analysis: model specific population value and confidence interval estimation. Statist Med 2004; 23: 2109-23.

38 Royston P. Explained variation for survival models. Stata J 2006; 6: 1-14.

39 Royston $P$, Sauebrei W. A new measure of prognostic separation in survival data. Stat Med 2004; 23: 723-48.

40 Nguyen CT, Kattan MW. How to tell if a new marker improves prediction. Eur Urology 2011; 60: 226-30.

41 Lloyd-Jones D. Cardiovascular risk prediction: basic concepts, current status and future directions. Circulation 2010; 121: 1768-77

42 Volavka J, Citrome L. Pathways to aggression in schizophrenia affect results of treatment. Schizophr Bull 2011; 37: 921-9.

43 Dean $K$, Walsh E, Moran $\mathrm{P}$, Tyrer $\mathrm{P}$, Creed F, Byford S, et al. Violence in women with psychosis in the community: prospective study. Br J Psychiatry 2006; 188: 264-70.

44 Monahan J, Steadman HJ, Appelbaum PS, Robbins PC, Mulvey EP, Silver E, et al. Developing a clinically useful actuarial tool for assessing violence risk Br J Psychiatry 2000; 176: 312-9.

45 Saha $S$, Chant D, Welham J, McGrath J. A systematic review of the prevalence of schizophrenia. PLOS Med 2005; 2: e141.

46 Wittchen $\mathrm{H}-\mathrm{U}$, Jacobi F, Rehm J, Gustavsson A, Svensson M, Jönsson B, et al. The size and burden of mental disorders and other disorders of the brain in Europe 2010. Eur Neuropsychopharmacol 2011; 21: 655-79.

47 Mathers C, Fat DM, Boerma J. The Global Burden of Disease: 2004 Update. World Health Organization, 2008.

48 Dolmén L. Criminality in Different Countries [in Swedish]. National Council for Crime Prevention, 2001.

49 Flynn S, Rodway C, Appleby L, Shaw J. Serious violence by people with mental illness: National Clinical Survey. J Interpers Violence 2014; 29: 1438-58.

50 Fazel S, Gulati G, Linsell L, Geddes JR, Grann M. Schizophrenia and violence: systematic review and meta-analysis. PLoS Med 2009; 6: e1000120.

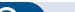

EXTRA 